\title{
Social Media and Nursing Today
}

\author{
Margaret Stroehlein* and Tina Bayer \\ Assistant Professor, Queensborough Community College, United States
}

Received: May 11, 2016; Accepted: June 23, 2016; Published: July 01, 2016

*Corresponding author: Margaret Stroehlein, Assistant Professor, Queensborough Community College, United States, E-mail: mstroehlein@qcc.cuny.edu; Tbayer@qcc.cuny.edu

According to Lambert, et al. [1], "Social media refers to the use of Web-based and mobile technologies to turn communications into an interactive dialogue. The content in social media is created by people using highly accessible and scalable technologies. It is a shift in how people discover, read, connect, and share information and content, typically with those who have similar interests. Social media transform monologues into dialogues and transform people from content readers into content publishers. (The terms social media and social networking are often used interchangeably.)" Lambert, et al. [1] further states, "Social networking is used to connect individuals with each other in an online format. Social media can take a variety of forms: • E-mail, an online mail account - Facebook, a social networking site with a profile that users themselves set up (712 million users) • MySpace, a music sharing and social networking site $\bullet$ LinkedIn, a professional networking site".

Social media is defined as sharing information online using conversational media that makes it easy to create and share content in the form of words, pictures, videos, and audios [2]. Social media has the advantage of allowing people to quickly access and share information. The use of social media and other electronic means of communication are constantly increasing related to the countless new social media platforms and applications. Three-quarters of all Americans use the internet, 93 percent of young adults use the internet on a regular basis [3]. More specifically, 77 percent of nursing and health science student's use Facebook [4]. These programs include blogs, social networking sites, as well as online chat rooms and forums. Nurses often utilize electronic media for both personal and professional use. However, there have been numerous instances where inappropriate uses of social media by nurses have been reported to the boards of nursing.

This paper will discuss some legal cases with social media in nursing and will share guidelines for nurses on the use of electronic media in a way that patient privacy and confidentiality are maintained.

Inappropriate use of social media by nurses causes concerns for employers, educators, and regulators. Employer concerns include the potential for damage to the reputation of the organization and liability for disclosure of protected health information [5,6]. Educators are concerned about boundary violations and privacy issues, which can affect relationships with clinical sites and the reputation of the nursing program $[7,8]$. The concerns of regulatory bodies center on the potential harm to patients and the public from the inappropriate use of social media $[9,10]$.

Nurses are using blogs, forums, and social networking sites to share their workplace experiences. Social media has given nurses opportunities in which they can express their feelings, reflect and even seek support from friends, colleagues, peers or anyone who is on the Internet. In addition, it has been identified that journaling and reflective practices are a basic element of any nursing practice [11].

Social media use has many benefits that can help our healthcare system. Just to mention a few, the uses include: fostering professional connections, facilitating and promoting timely communication with both patients and their family members, in educating consumers and health care professionals. Health care social media sites such as the Mayo Clinic Social Media Health Network and KevinMD.com use social media to provide a platform for health care organizations and providers to interact with one another as well as with patients and consumers [12]. The American Physical Therapy Association (APTA) has a strong social media presence. In addition to the APTA Online Communities, the organization maintains 8 active Twitter accounts (3 event-specific accounts, 3 Facebook pages, 2 YouTube channels, and 1 LinkedIn group) (American Physical Therapy Association. Social Media \& Networking. Available at: http:// www.apta.org/socialmedia/.) Each of these social media sites provides specific, unique opportunities for information sharing among members, nonmembers, students, event attendees, other health care professionals, and consumers [12].

The Internet is often helpful for nurses; however without caution nurses can disclose too much information, which may result in violating both patient privacy and confidentiality. To control mishaps, health care organizations have come up with strategies that oversee the use of online networking and social media sites by employees at the workplace. Institutional policies deal with the issues of personal use of employer computers, as well as addressing personal social media use during working hours [13]. These policies often address the types of websites that can be used and accessed by the employee. Nurses may face 
potentially serious consequences for inappropriate use of social media within the workplace [14]. Guidelines established by the NLN provide a foundation for institutional policies. "As stated in the NLN white paper [15]; "Instances of inappropriate use of social and electronic media may be reported to the BON. The laws outlining the basis for disciplinary action by a BON vary between jurisdictions. Depending on the laws of a jurisdiction, a BON may investigate reports of inappropriate disclosures on social media by a nurse on the grounds of: Unprofessional conduct; Unethical conduct; Moral turpitude; Mismanagement of patient records; Revealing a privileged communication; and Breach of confidentiality"

Patient confidentiality and privacy are serious matters in health care. The nurse must safeguard any patient information obtained during treatment. When information must be disclosed, it must be with patient consent, and necessary to the health care team to provide safe competent care. In addition, confidential information can only be disclosed if legally required or on the requirement that the information revealed won't bring any harm to the patient. Beyond these limited exceptions, it is the nurse responsibility and obligation to safeguard such information universally [11].

Federal laws also enforce defined privacy and confidentiality through Health Insurance Portability and Accountability Act (HIPAA) which are intended to protect patient privacy by giving meaning to identified information and how it may be used under which circumstances. Breach of patient confidentiality or privacy may be reported to Board of Nursing (BON), which operates under law outlining the premise for disciplinary move to be made. Depending on the law of the jurisdiction, an investigation is conducted on the inappropriate disclose by the nurse. If the allegations about the nurse are found to be true, the BON has the mandate of reprimanding, applying sanctions and possible assessment of monetary fines or temporary as well as permanent loss of the licensure [16].

As stated by Westrick [17], the case Yoder v [18]. University of Louisville is an example of poor judgment by a nursing student. A nursing student posted unfavorably on my space about a patient cared for during the obstetrics clinical experience. The school found out and wanted the student expelled. The final result was that the student was allowed to return to school and that University policies needed to be clear regarding social media [19]. Another example of nursing misuse in social media involved breaking HIPAA regulations. A nursing student posted a photo of a pediatric cancer patient on Facebook; someone saw it and reported it to a supervisor at the hospital. The student was expelled from the program. Further, the nursing program was not allowed to come back to the children's hospital for pediatric clinical experiences and the hospital faced HIPAA violations [20]. This next case illustrates the importance of censoring what is posted on Facebook. As stated by Hader [21], "two nurses in Wisconsin were investigated by the Federal Bureau of Investigation (FBI) for possible federal violations after a photograph of an x-ray image showing a sexual device lodged in a patient's rectum was posted and discussed on one of the nurse's
Facebook pages. A local sheriff's investigation determined that 2 nurses had photographed the x-ray and at least one posted it online. The nurses were fired for violating company policy and, in addition to the FBI investigation, may also face discipline from their state licensing board". [21]

It is important to recognize that there are cases of inappropriate use of social media by nurses but with awareness nurses can avoid disclosing confidential or private information about patients [22]. Nurses need to maintain and keep professional boundaries all times as they engage in the use of electronic media [23].

The following guidelines can help nurses minimize the risks associated with the use of social media:

- Nurses are restricted from transmitting images that are related to the patient by the use of electronic media [23].

- Sheldon, et al. [11] state "Nurses are barred from transmitting any kind of information that may anticipate or influence the violation of patients' rights to privacy and confidentiality “.

- According to Spector, et al. [20] "It is expected nurses to maintain and keep professional boundaries at all times in the use of electronic media. Similarly to person relationships, the nurse has a duty of establishing, communicating and enforcing professional boundaries with patients in all online environments. Nurses must be cautious when having online social contact with patients or former patients. Nurses are always expected to consult with the policies of the employer on the appropriateness that regards work related relationships"

- $\quad$ As stated by Zerwekh, et al. [14] "Nurses are always expected to consult with the policies of the employer on the appropriateness that regards work related posting. Nurses are expected to report any form or; identified breach of confidentiality or privacy. This is done with complying with the policies of the 'employer regarding the use of employer-owned gadgets like computers, cameras and other electronic devices and the use of personal devices at the workplace"

- According to Bonsall, etal. [24],"Nurses are also prohibited from making remarks about employers and coworkers. Even if freedom of speech is guaranteed, nurses are not allowed to make threatening, harassing, profane, obscene, sexually explicit, racially derogatory, and homophobic or any other kind of offensive sentiments. Moreover, nurses are banned in posting content or speaking on behalf of the employer unless they have been authorized and they should always follow all the applicable policies required by the employer".

In conclusion, social and electronic media in nursing are here to stay. We need to understand the benefits and risks of social media in nursing. Nurses need to know the possible ramifications of disclosing patient related information through social media. 
In addition, nurses need to be aware of employer policies, University policies, relevant state and federal laws. By being careful, professional, conscientious both nurses and patients can benefit from social media.

\section{References}

1. Lambert KM, Barry P, Stokes G. Risk management and legal issues with the use of social media in the healthcare setting. J Healthc Risk Manag. 2012;31(4):41-7. doi: 10.1002/jhrm.20103.

2. Hanson C, West J, Neiger B, Thackeray R, Barnes M, McIntyre E. Use and acceptance of social media among health educators. American Journal of Health Education. 2011;42(4):197-204.

3. Lenhart A, Purcell K, Smith A, Zickuhr K. Social Media and Young Adults. Pew Research Center: Internet, Science \& Tech http://www. pewinternet.org/2010/02/03/social-media-and-young-adults/

4. Giordano C, Giordano C. Health professions students' use of social media. J Allied Health. 2011;40(2):78-81.

5. Genova GL. No place to play: Current employee privacy rights in social networking sites. Business and Professional Communication Quarterly. 2009;72:97-101.

6. Eira I. Klich-Heartt, Susan Prion. Social networking and HIPAA: Ethical concerns for nurses. Nurse Leader. 2010;8(2):56-58. doi:10.1016/j. mnl.2010.01.007.

7. Lehavot K. "My Space" or yours? The ethical dilemma of graduate students' personal lives on the Internet. Ethics and Behavior 2009;19(2):129-141.

8. Trossman S. Sharing too much? Nurses nationwide need more information on social networking pitfalls. American Nurse Today. 2010;3839.

9. Janet Anderson, Karen Puckrin. Social Network Use: A Test of SelfRegulation. Journal of Nursing Regulation. 2011; 2(1):36-41.

10. Spector N. Boundary violations via the Internet. Texas Board of Nursing Bulletin. 2010;41(3):6.

11. Sheldon LK, Foust J. Communication for nurses: Talking with patients.
Third Edition. 2014.

12. Gagnon K, Sabus C. Professionalism in a digital age: opportunities and considerations for using social media in health care. Phys Ther. 2015;95(3):406-14. doi: 10.2522/ptj.20130227.

13. Sewell J, Thede L. Informatics and nursing: Opportunities and challenges. Philadelphia: Wolters Kluwer Health/Lippincott Williams \& Wilkins; 2013.

14. JoAnn Zerwekh, Garneau AZ. Nursing today: Transition and trends, 8th Edition. 2015

15. White paper: A Nurse's guide to the use of social media. 2011. Retrieved from https://www.ncsbn.org/Social_Media.pdf

16. Finnegan G. Social Media for Nurses - Educating Practitioners and Patients in a Networked World Social Media for Nurses. Nurs Stand. 2013;27(31):30. Doi: 10.7748/ns2013.04.27.31.30.b1489.

17. Westrick SJ. Nursing Students' Use of Electronic and Social Media: Law, Ethics, and E-Professionalism. Nurs Educ Perspect. 2016;37(1):16-22.

18. Yoder v. University of Louisville, 2012 WL 1078819 (W.D. Ky., Mar. 30,2012 ).

19. Appeals court upholds blogging-related expulsion of student from nursing school [Web log post]. (n.d.). Retrieved from https://www. insidehighered.com/news/2013/06/06/appeals-court-upholdsblogging-related-expulsion-student-nursing-school

20. Spector N, Kappel DM. Guidelines for using electronic and social media: The regulatory perspective. Online J Issues Nurs. 2012;17(3):1.

21. Hader AL, Brown ED. Patient privacy and Social Media. AANA J. 2010;78(4):270-4

22. Schmitt TL, Lilly K. Social media use among nurses. Journal of the Dermatology Nurses Association. 2012;4(3):181-187.

23. Skiba DJ. Nursing education 2.0: The need for social media policies for schools of nursing. Nurs Educ Perspect. 2011;32(2):126-7.

24. Bonsall L, Schoenly L. Understanding Social Media Lingo. Journal of the Dermatology Nurses' Association. 2012;4(3);195-196. Doi: 10.1097/jdn.0b013e318256e91c. 